\title{
Burkhard Madea, Pekka Sauko (eds.): Forensic medicine in Europe
}

\author{
Schmidt-Römhild, 2008, 461 pp, paperback, ISBN 978-3-7950-0334-0
}

\author{
Saskia S. Guddat
}

Published online: 27 February 2009

(C) Humana Press 2009

Since the foundation of the European Union (EU) in 1957 (which initially consisted of six countries), the EU has grown to become one of the most important economic regions in the world, consisting of 27 member states with a population of over 491 million people. The EU was founded to unify the member states economically and politically, which has led, for example, to a common currency. Since countries are growing closer together, it is necessary for those involved in death investigation to know about the different scientific and medico-legal systems. The editors of this book have approached the questions of differences by inviting well-recognized representatives from each member state of the EU to write about the situation in their countries. They were asked to cover different items such as the history of forensic medicine in their own country (including the principle scientists, significant textbooks or journals, and main areas of research), the structures of forensic services (university-associated or other, financing, provision of services, such as autopsies, clinical forensic medicine, paternity testing etc.), details of the respective national societies of forensic medicine, current developments, and national and international co-operations.

This highly interesting book is divided into 28 chapters that deal with the history and the organization of legal medicine in Austria, Belgium, Cyprus, the Czech Republic, Denmark, England and Wales, Estonia, Finland, France, Germany, Greece, Hungary, Ireland, Italy, Latvia, Lithuania, Luxembourg, Maltese Islands, Netherlands, Norway, Poland, Portugal, Scotland, Slovak Republic, Slovenia, Spain, Sweden, and Switzerland.

Since the configuration of each chapter is similar because of the items that the authors of the chapters were asked to cover it is possible for the reader to compare single items in different countries. The chapters are very interesting to read, especially the history and the development of forensic medicine in each member state of the EU. The addresses of all of the institutes also facilitate contact and communication between colleagues. All in all, this is a very interesting book for everyone working in forensic medicine in Europe. 